\title{
Influence of Tropical Cyclones on the Estimation of Climate Variability in the Tropical Western North Pacific
}

\author{
Huang-Hsiung Hsu, Ching-Hui Hung, An-Kai Lo, and Chun-Chieh Wu \\ Department of Atmospheric Sciences, National Taiwan University, Taipei, Taiwan \\ ChiH-Wen Hung \\ Department of Atmospheric Sciences, Chinese Culture University, Taipei, Taiwan
}

(Manuscript received 10 January 2007, in final form 12 July 2007)

\begin{abstract}
By estimating the differences between the original and tropical cyclone (TC)-removed fields derived from the 40-yr (ECMWF) Re-Analysis (ERA-40) and NCEP-NCAR 40-Year Reanalysis, this study reveals that TCs contribute significantly (exceeding $50 \%$ in certain regions) to the seasonal mean and the intraseasonal and interannual variance of the 850 -hPa vorticity along the TC tracks in the tropical western North Pacific. Similar effects on the precipitation are also seen, as presented by the examples located in Taiwan. While the low-frequency, large-scale circulation produces a clustering effect on TCs, the latter, which has a large positive vorticity and tends to occur in the positive vorticity background flow, significantly enhances the strength of the positive vorticity. The contribution from TCs, which is not offset by the synoptic systems with weak negative vorticity, can therefore leave marked footprints in the climate signal and variability. This effect is not removed by long-term averaging and low-pass filtering, which are often used to retrieve the climate perturbations. This study reveals that the climate variability, as it is defined, is not contributed to merely by the low-frequency large-scale fluctuations. Instead, the TC effect has to be taken into account to understand the climate variability in the tropical western North Pacific. Subsequently, the ensemble effect of TCs, at least in the statistical sense, has to be resolved in the climate model to obtain a better simulation of the climate variability in the TC-prone region, such as the tropical western North Pacific.
\end{abstract}

\section{Introduction}

A climate system is characterized by the interactions between multiscale fluctuations. Estimation of the climate variability in different time scales is one of the cornerstones of climate research. Traditionally, time averaging and filtering are often used to numerically retrieve the low-frequency climate signals. The corresponding climate variability is estimated by calculating the variance. Such an approach is based on an implicit assumption that the time averaging and filtering processes remove higher-frequency signals. This assumption is normally not violated, as long as the amplitudes of the high-frequency fluctuations in the positive and negative phases are almost equal, and the averaging time is long enough to undergo several complete highfrequency fluctuation cycles.

On the other hand, the assumption may still be vio-

Corresponding author address: Huang-Hsiung Hsu, Department of Atmospheric Sciences, National Taiwan University, Taipei, Taiwan.

E-mail: hsu@atmos1.as.ntu.edu.tw lated when the high-frequency fluctuations of significantly different amplitudes in the positive and negative phases are embedded in the time series, or when the step function-like fluctuations of large amplitude have the tendency to exist in one particular fluctuation phase. To demonstrate this effect on the time mean and variance, 150 time series of a combination of two sinusoidal waves with random errors, that is, $x=x_{0}+$ $\left(a_{1} \cos t+b_{1} \sin t\right)+\left(a_{3} \cos 3 t+b_{3} \sin 3 t\right)+\epsilon$, were created to simulate 150 typhoon seasons. One to six step function-like perturbations with much larger amplitudes, representing the occasionally occurring extreme events, were randomly added to the 150 time series. Three time series are shown in Fig. 1 as examples. Without considering the extreme values, the ensemble mean and "inter-time series" (interannual) variance, which are defined as the variance of the 150 time series means, are 55.7 and 0 , respectively. Zero variance is found, as the 150 time series are different only in the wake of random noises. Therefore, the corresponding means are essentially the same for all series. By adding these extreme values, the ensemble mean and interan- 


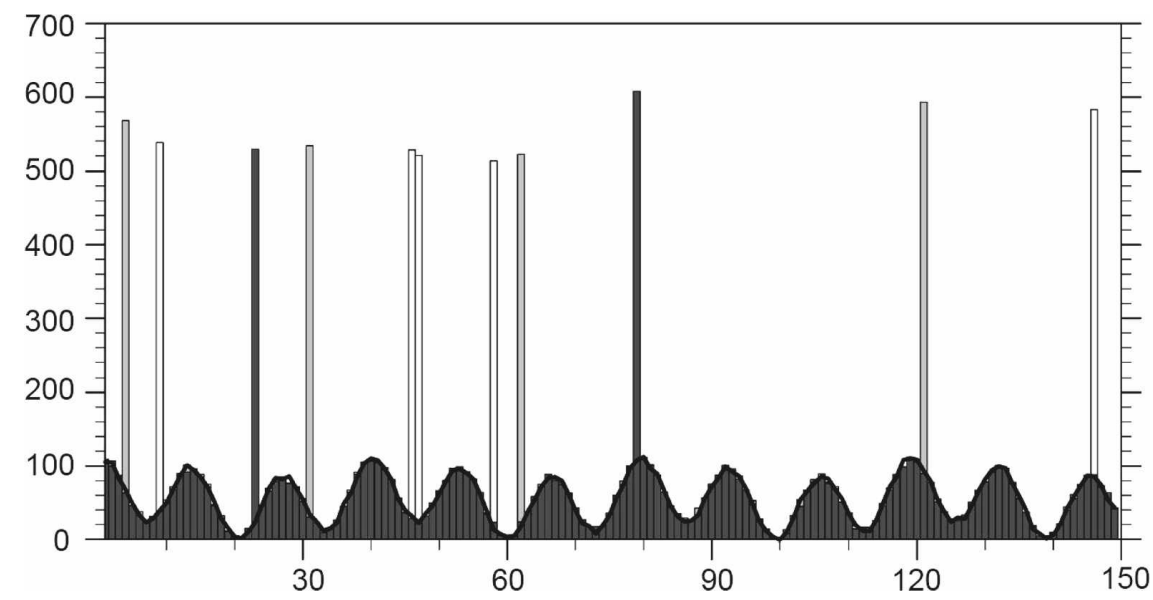

FIG. 1. Three samples of 150 synthetic time series (see text) with randomly added step function-like perturbations are revealed in demonstrating the effect of extreme values on the estimation of the mean and variance. Extreme values of three time series are shown by the solid bar, gray bar, and hollow bar. Only one sinusoidal curve is shown here, as the three sinusoidal curves differ only by negligible random noises. The $X$ and $Y$ axes indicate the time and strength of waves and perturbations, respectively.

nual variance increase significantly to 65.1 and 18.8 , respectively. The presence of these extreme values obviously increases the mean of each time series to different levels, depending on the amplitude and number of extreme events, which indirectly raises the variance between the means of the time series. This example reveals the possibility that the occurrence of a few extreme events may significantly enlarge the ensemble mean and variability.

Similar effects on the climate variability may occur in the areas where tropical cyclones (TC) are active, such as the tropical western North and South Pacific, the tropical North Atlantic, and the tropical Indian Ocean. This is because TCs are vortices of strong positive vorticity, which is not accompanied (or compensated) by vortices of negative vorticity with roughly equal strength. As demonstrated in Fig. 1, the climate variability in the TC-prone areas may enlarge because of the occurrence of TCs. It has been known that TC activity is often modulated by low-frequency fluctuations such as intraseasonal oscillation (ISO; Gray 1978; Nakazawa 1986; Heta 1990; Liebmann et al. 1994; Maloney and Dickinson 2003), El Niño-Southern Oscillation (ENSO; Chan 1985, 2000; Chen et al. 1998, 2004; Landsea 2000; Chia and Ropelewski 2002; Wang and Chan 2002), and even decadal fluctuation (e.g., Ho et al. 2004). While TCs tend to appear in clusters, in light of the modulation of these low-frequency fluctuations, the mean vorticity in the TC-active periods is likely to be larger than its counterpart in the TC-inactive periods. This asymmetric effect on the mean vorticity in the different phases of the low-frequency fluctuations may therefore lead to an increase in the low-frequency variance. The climate variability may therefore be larger under the existence of TCs.

Although the significant effects from TCs may change our interpretation of the climate variability in the TC-prone region, it is minimally understood, as little attention has been addressed to this important issue. In this study, an unconventional approach was employed in removing the TCs from the global analysis. In addition, the potential contribution of TCs was estimated, which is defined as the variance difference between the original and TC-removed vorticity fields at $850 \mathrm{hPa}$. The approach adopted in this study was designed to shed light on the TC contribution to the climate variability along the TC tracks. Our results indicate that the differences in the time mean and variance are large enough for concern in the intraseasonal and interannual time scales. The arrangement of this article is as follows. Methodology and data are described in section 2. Effects on the interannual and intraseasonal variability are presented in section 3. A comparison between different global analyses is shown in section 4, while the conclusion and discussion are given in section 5 .

\section{Data and methodology}

In reality, because of the possible nonlinear $\mathrm{TC}-$ climate interaction, it is impossible to exactly quantify the TC contribution. This essentially holds true for all studies involving multiple temporal and spatial scales. Despite this concern, temporal and spatial filtering has often been used to decompose a total field into pertur- 


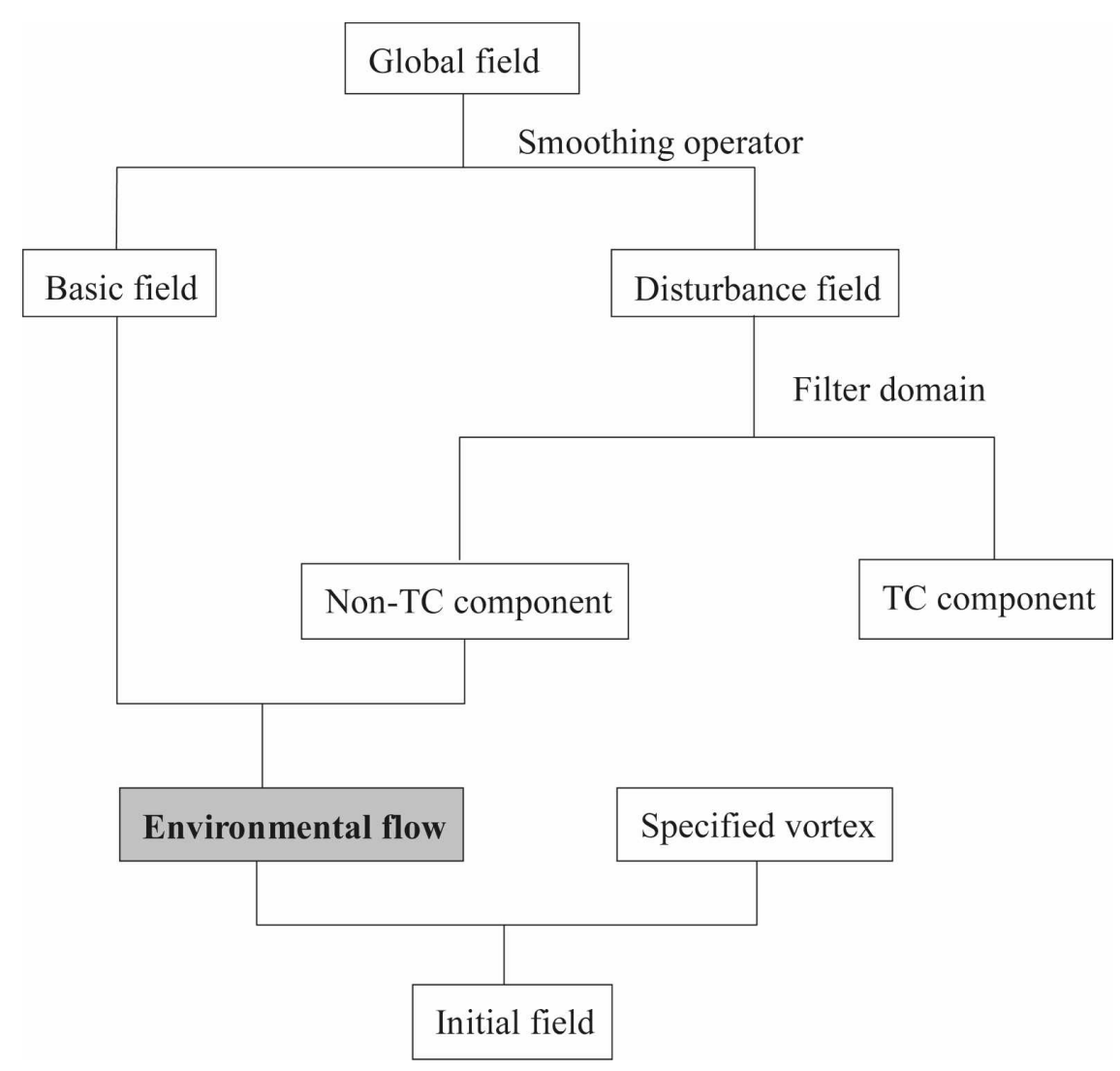

FIG. 2. Flowchart of the TC-removal procedure.

bation and mean flow, or even into several subfields of distinct temporal or spatial scales. This linear-thinking approach has proved useful in providing important insights into climate processes, for example, the wavemean flow interaction. To evaluate the possible TC contribution to climate variability, a spatial-filtering approach was taken to remove the TC vortices from the 40-yr European Centre for Medium-Range Weather Forecasts (ECMWF) Re-Analysis (ERA-40; $2.5^{\circ}$ longitude $\times 2.5^{\circ}$ latitude; Uppala et al. 2005) at $850 \mathrm{hPa}$ in the typhoon season (June-October) from 1980 to 2004. This filtering procedure is similar to the decomposition of the total field into perturbation and background flow, but is performed in a more sophisticated manner. In contrast to the pre-1980 period, the 1980-2004 period was chosen in consideration of the better satellite network observation in pinpointing the TC position more accurately. The same analysis procedure was also applied to the 1958-79 period for comparison. The potential contribution of TCs to the climate variability was estimated by calculating the difference between the variance of the original and TC-removed vorticity at $850 \mathrm{hPa}$.

Both interannual and intraseasonal variances are ex- amined in this study. The interannual variance is defined as the variance of seasonally averaged $850-\mathrm{hPa}$ vorticity in each typhoon season. A 20-80-day Butterworth bandpass filter was used to extract the intraseasonal fluctuations from the daily mean vorticity. To reduce the end effect of the Butterworth filter, only data from 16 June to 15 October were used to calculate the intraseasonal variance.

Removal of TCs from the analysis data has been a common practice in the typhoon and hurricane simulation and forecast. The procedure, which has been used in the Geophysical Fluid Dynamics Laboratory (GFDL) hurricane prediction system (Kurihara et al. 1993, 1995) and in typhoon simulations (Wu et al. 2002) for enhancing the representation of the environmental field in the initial condition, has proved effective in improving the overall TC track forecast. Following the procedure proposed by Kurihara et al. $(1993,1995)$, the four-time daily $850-\mathrm{hPa}$ winds associated with each TC, based on the Joint Typhoon Warning Center (JTWC) best track, were subtracted from the $850-\mathrm{hPa}$ wind field during the typhoon season.

The basic procedure, demonstrated in Fig. 2, is briefly described as follows. Readers are referred to 
Kurihara et al. (1993, 1995) for details. The zonal and meridional winds were individually separated into basic and disturbance fields using a smoothing operator. The winds associated with a TC were isolated in the filter domain, which defines the extent of a TC in the global analysis, and subtracted from the disturbance field to create a non-TC component. In the procedure, $1200 \mathrm{~km}$ is specified as the filter domain. This does not mean that everything in the domain is identified as the TC component. It is simply the longest distance for the procedure to automatically search the effective radius of a $\mathrm{TC}$ in 24 directions (for every $15^{\circ}$ ) surrounding the $\mathrm{TC}$ center. When the radius of a TC, for example, 500 $\mathrm{km}$, is identified in a particular direction, the searching stops, and only the TC winds within the radius are subtracted. The reason for choosing a larger domain is to avoid missing the TC circulation in a TC (or typhoon) that owns a large radius and therefore leading to the underestimation of the TC circulation. After removing the TC component from the disturbance field, the nonTC component was added to the basic field to form the environmental flow, which is the TC-removed wind field in this study. The environmental flow outside the filter domain is identical to the original global analysis. The original and TC-removed vorticity fields were calculated based on the corresponding wind fields.

The procedure described above was able to correctly separate the TC and environmental components. One example is shown in Fig. 3a when three typhoons appeared simultaneously in the western North Pacific at 0600 UTC 28 August 2001. The three typhoons, lining up from the west to east near $20^{\circ} \mathrm{N}$, were embedded in a zonally elongated belt of positive vorticity, which reflects a well-established monsoon trough and a favorable condition for the tropical cyclogenesis and development (Elsberry 2004). They appeared as three isolated vortices in Fig. 3b, after being separated from the background flow. The environmental flow, shown in Fig. 3c, was clearly characterized by a zonally elongated (but weaker) monsoon trough across the South China Sea and the Philippine Sea. This result, as with many other cases, indicates that the TC removal procedure removes mainly the $\mathrm{TC}$ vortex, and accurately retains the large-scale circulation, along with the climate variability contributed by the large-scale fluctuations.

One potential problem in removing TCs from the global analysis, such as the ERA-40, is the possible mismatch between the JTWC TC track, which defines the center of a TC, and the position of the TC-corresponding vortex in the ERA-40. This is partially attributed to the coarse resolution of the datasets used in this study. The JTWC best track and the ERA-40 were not thoroughly cross-checked, as the main goal of this study is (a) Total

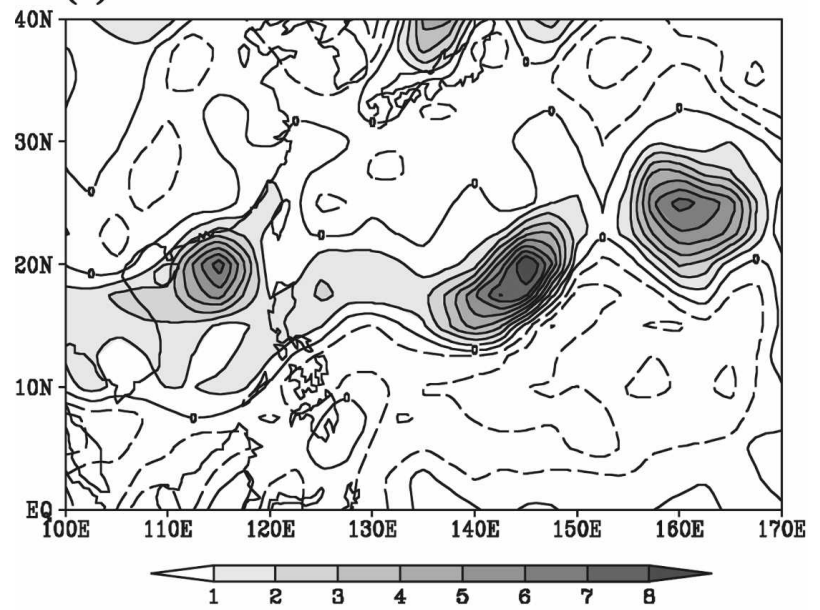

(b) TC

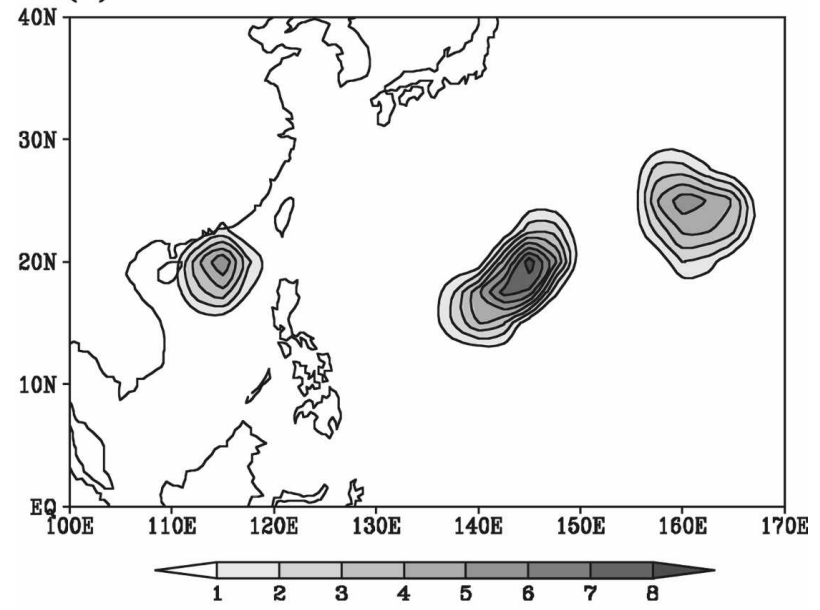

(c) TC-removed

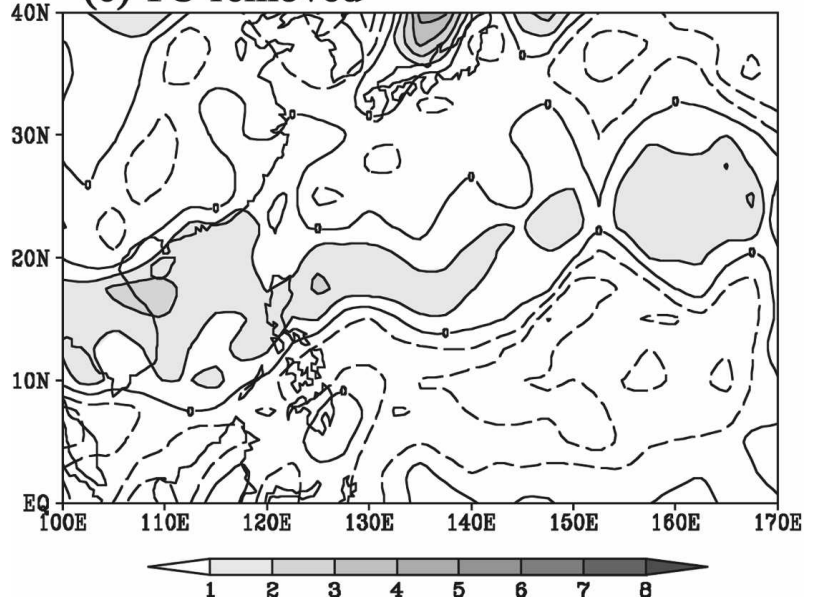

FIG. 3. The 850 -hPa vorticity fields on 0600 UTC 28 Aug 2001 when three typhoons existed simultaneously in the tropical western North Pacific: (a) total, (b) TC, and (c) TC removed. Contour interval is $10^{-5} \mathrm{~s}^{-1}$. Solid and dashed lines denote positive and negative vorticity, respectively. 
to statistically assess the gross contribution of TCs to the climate variability in a large domain covering the entire tropical western North Pacific. A mismatch of a few degrees in latitude and longitude would not seriously affect the overall results. As it will be shown later, the removed vorticity is collocated nicely with the TC tracks. The possible mismatch does not seem to cause problems in this study. TCs may be presented differently in different global analysis or in different resolution. Comparisons between the ERA-40 and National Centers for Environmental Prediction-National Center for Atmospheric Research (NCEP-NCAR) 40-Year Reanalysis and between different spatial resolutions were carried out. The results shown in section 4 indicate the consistency between the analyses.

Another concern is the underrepresentation of the wind speed and vorticity of TC in the ERA-40. This is an existing problem, which cannot be solved in this study. This study's goal is to demonstrate how TCs contribute significantly to climate variance, based on presently available global analysis. The results should be viewed as the TC effect represented in currently available global analysis, which has been widely used to estimate the climate variability. If the exact location and strength of TCs are represented in the global analysis, the actual contribution of TCs will likely be larger than what was found in this study.

\section{Interannual variability}

It is implicitly assumed that long-term averaging would eliminate (or minimize the contribution of) the transient perturbations, such as TCs, which fluctuate in a period much shorter than the averaging period. If this were true, the seasonal means from June to October for both the original and TC-removed fields would be almost the same. Figure 4 presents the seasonally averaged $850-\mathrm{hPa}$ vorticity and TC tracks for the two contrasting typhoon seasons 1994 and 1998. Based on the statistics available from the Regional Specialized Meteorological Center (RSMC) Tokyo-Typhoon Center http://www.jma.go.jp/jma/jma-eng/jma-center/rsmchp-pub-eg/RSMC_HP.htm), the total amount of named TCs in June-October (JJASO) 1994 and 1998 were 32 and 11 , respectively, compared to the climatologicalmean number of 20. The former (latter) is the year with the largest (least) number of named TCs during the typhoon seasons from 1951 to 2005.

During the 1994 typhoon season, the TC tracks can be roughly divided into three types (Fig. 4a). The first type follows a west-northwestward direction, crossing straightly from the Philippine Sea to the South China Sea. The second type moves northwestward in the Phil- ippine Sea and recurves north-northwestward when approaching Taiwan. The third type moves northward, covering a wide range of longitudes across the subtropical western North Pacific. The seasonal-mean 850-hPa vorticity (Fig. 4b) exhibits maximum positive values (i.e., cyclonic) near these TC tracks, where the largest amplitude is found in the Philippine Sea and South China Sea. Along the TC tracks, there is always a local maximum of mean vorticity in both typhoon seasons. During the 1998 typhoon season, the TCs moved in many different directions in a less-organized manner (Fig. 4d). The genesis locations of TCs were located to the northwest of the climatological-mean position. The seasonal-mean $850-\mathrm{hPa}$ vorticity was negative in the Philippine Sea and the subtropical western North Pacific, while the positive vorticity appeared only in the western South China Sea (Fig. 4e). These features reflect the characteristics that are often observed in the La Niña summer: fewer TCs, northwestward shift of TC genesis region, and weaker monsoon trough (Chia and Ropelewski 2002; Wang and Chan 2002).

Although the overall vorticity pattern in 1994 looked similar after the TC removal, notable changes can be seen in the Philippine Sea and South China Sea where the TC tracks were observed (Fig. 4c). For example, the positive mean vorticity in the Philippine Sea weakens significantly from above $9 \times 10^{-6} \mathrm{~s}^{-1}$ to less than $3 \times$ $10^{-6} \mathrm{~s}^{-1}$. The largest reduction observed in the center of the positive mean vorticity exceeds $6 \times 10^{-6} \mathrm{~s}^{-1}$ (Fig. $4 \mathrm{a}$ ), accounting for more than $60 \%$ of seasonal-mean values. Similar changes can also be seen north of $20^{\circ} \mathrm{N}$ where northward but less-organized tracks were found. After removing TCs, the negative vorticity exhibits larger amplitudes and a more coherent spatial structure. The change indicates a stronger and more coherent subtropical anticyclone after the removal of TCs.

In contrast, the TCs in the 1998 typhoon season seem to have a much smaller effect on the seasonal-mean vorticity. Although the mean TC-removed vorticity along the TC tracks tend to show a higher negative value in the Philippine Sea and the subtropical western North Pacific (Figs. 4e,f), the changes are much smaller than in 1994 (Fig. 4d). The comparison between the 1994 and 1998 typhoon seasons indicates that the degree of the TC effect on the seasonal-mean vorticity likely depends on the TC activity.

The results shown above indicate that TCs, although having a lifetime much shorter than the time span of the typhoon season, leave nonnegligible footprints in the 5 -month seasonal means. Two factors may contribute to this effect. First, a TC is the strongest synoptic disturbance in the tropical western North Pacific. There is 
(a) TC and TC track

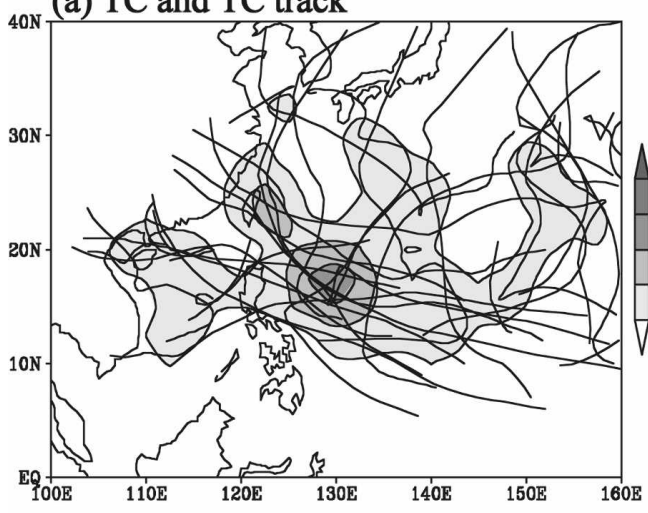

(b) Total
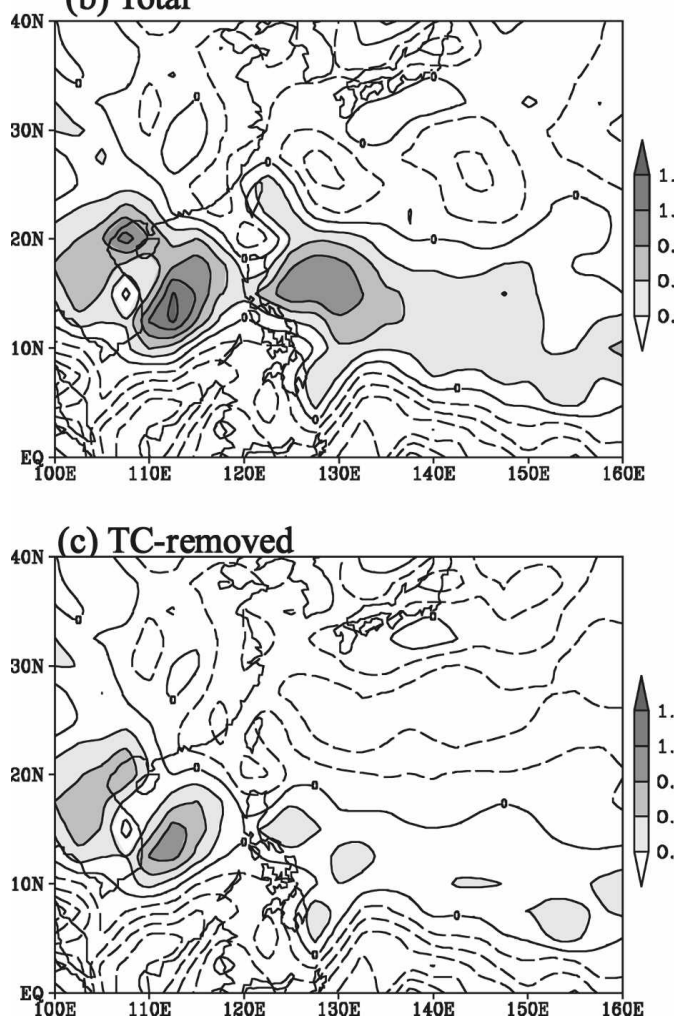

(d) TC and TC track

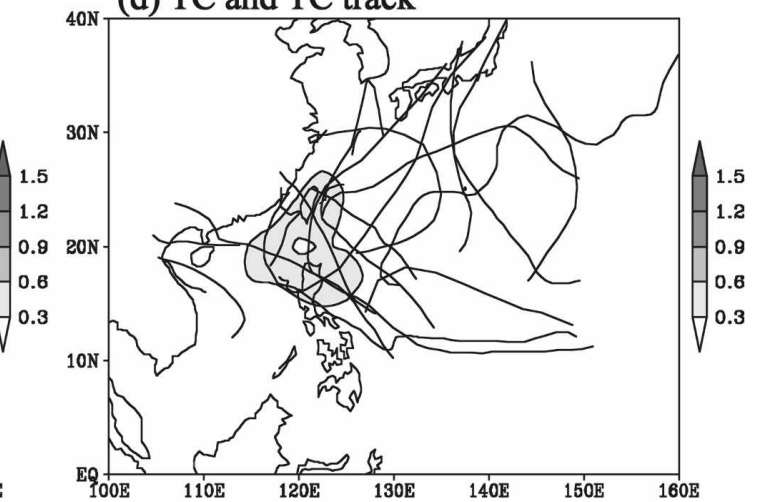

(e) Total
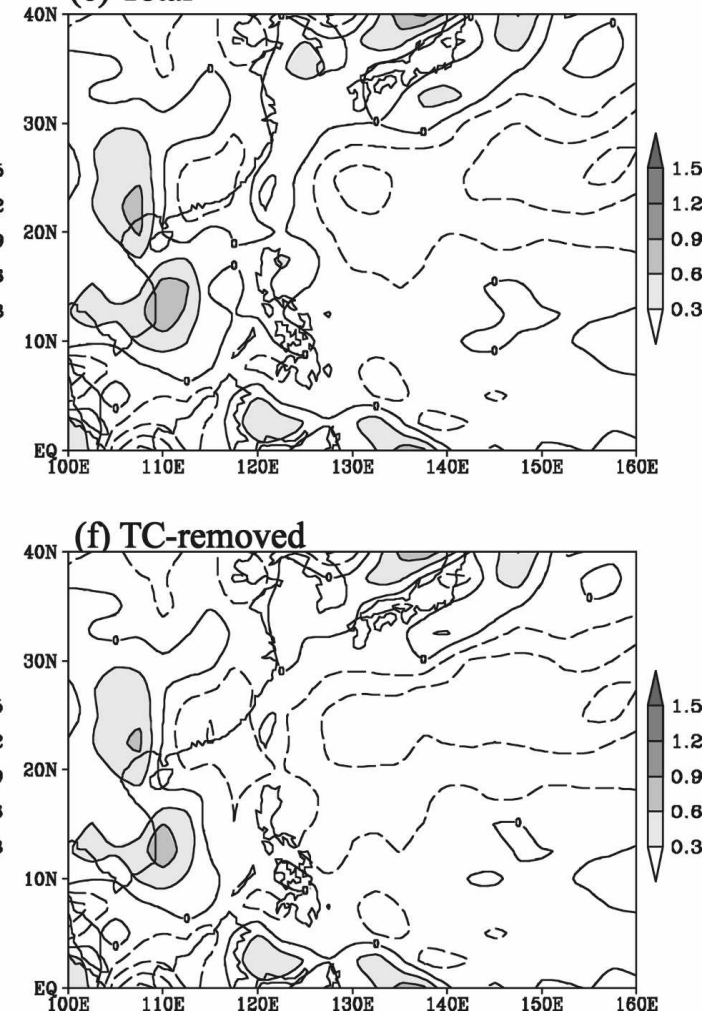

FIG. 4. Seasonal means of 850-hPa vorticity in JJASO (a)-(c) 1994 and (d)-(f) 1998: (a), (d) TC component and TC tracks; (b), (e) total; and (c), (f) TC removed. Contour interval is $0.3 \times 10^{-5} \mathrm{~s}^{-1}$. Solid and dashed lines denote positive and negative vorticity, respectively.

no other synoptic feature with a negative vorticity strong enough in canceling out the contribution of the cyclonic vorticity associated with TCs. Second, TCs tend to be clustered by the large-scale circulation and move more or less along similar tracks. Under these circumstances, the clustering of strong vortices like TCs is likely to enlarge the seasonal-mean vorticity along the clustered tracks. These results are contrary to the assumption stated in the beginning of this section.

As seen in the comparison between the 1994 and
1998 typhoon seasons, the TC number and degree of clustering in the tropical western North Pacific vary significantly from year to year, depending on the characteristics of the large-scale circulation such as the monsoon trough and the Pacific subtropical anticyclone, which are in turn affected by other climate factors, such as ENSO. It follows that the TC contribution to the seasonal mean is likely different from one year to another. In view of these marked differences for each year, the interannual variance, which is interpreted as 

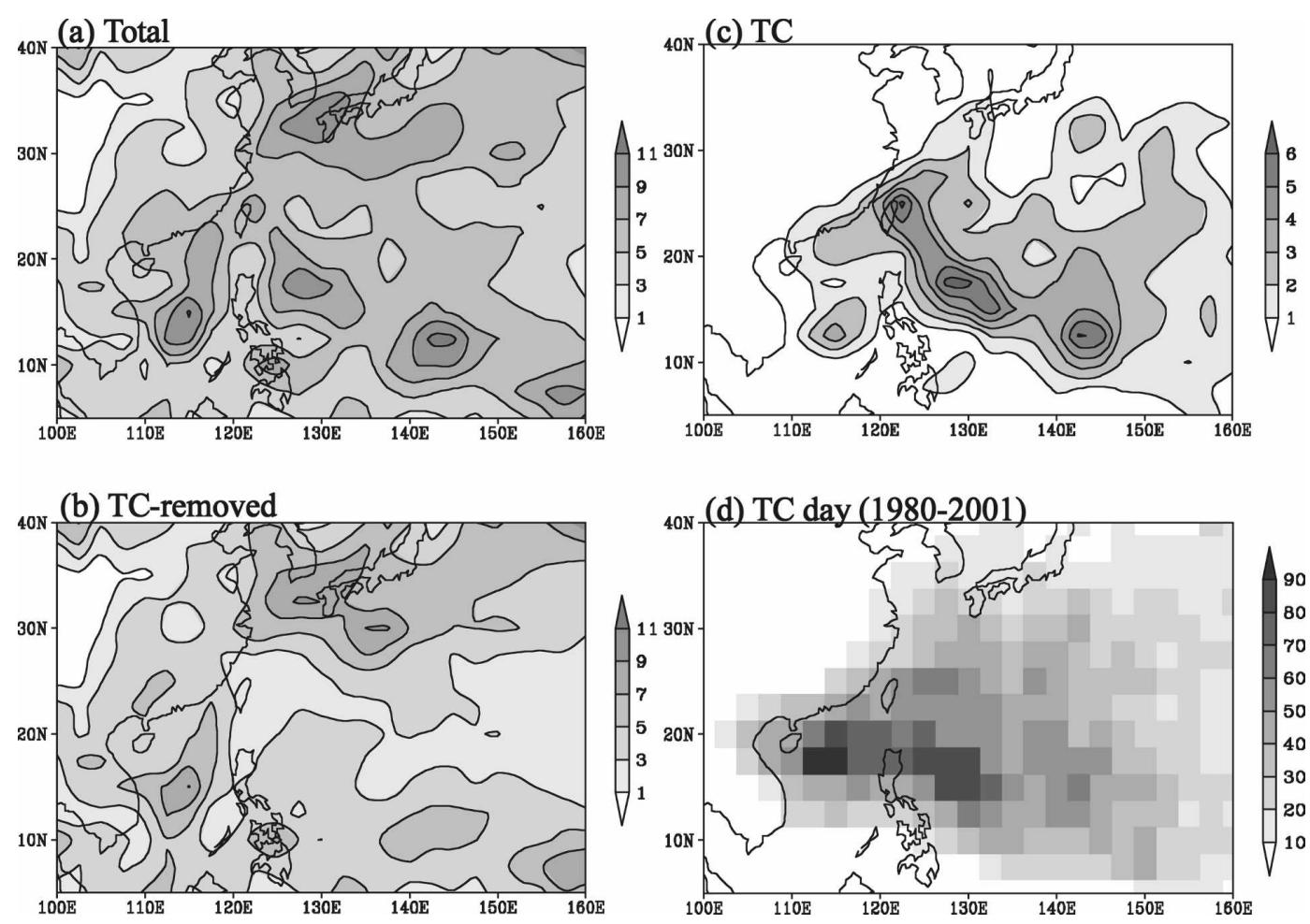

FIG. 5. Interannual variance of 850-hPa vorticity in 1980-2001: (a) total, (b) TC removed, (c) TC, and (d) accumulated TC occurrence distribution. Contour interval is $2 \times 10^{-12} \mathrm{~s}^{-2}$ in (a) and (d) and $1 \times 10^{-12} \mathrm{~s}^{-2}$ in (c).

the variability of seasonal means, is likely affected by the existence of TCs.

To examine this issue, the interannual variances of 850-hPa vorticity, which is computed based on the seasonal mean of each year, for the original and TCremoved fields from 1980 to 2001 are shown in Fig. 5. In the original field, a large vorticity variance is observed in the Philippine Sea and the tropical western North Pacific, the region surrounding Taiwan, the East China Sea and the Pacific to the south of Japan, and the South China Sea (Fig. 5a). In the TC-removed variance shown in Fig. 5b, the variance reduces notably in the Philippine Sea, the tropical western North Pacific and the region surrounding Taiwan. The regions with major differences shown in Fig. 5c are clearly collocated with the TC occurrence distribution seen in Fig. 5d. The reduction in variance, expressed in percentage, is shown in Fig. 6a. A reduction exceeding $50 \%$ is found along the TC tracks from the tropical western Pacific to Taiwan.

Similar results were also obtained in the analysis during 1958-79 and the entire 1958-2001 period. The reduction in percentage for both periods is shown in Figs. 6 b,c. The spatial patterns in both time frames are similar to the pattern in 1980-2001 (Fig. 6a). Among the three periods, the reduction is largest in 1980-2001 and smallest in 1958-2001. The region of major reduction in 1958-79 is largely located to the northeast of its counterpart in 1980-2001. The reason for this difference is not clear. More satellite observations and surveillances in recent decades may yield a better representation of TC structures in the analysis, which may lead to larger reductions. Whether the region shift between two subperiods is significant enough requires further investigation. The TC occurrence distribution in 1958-2001 is also presented in Fig. 6d. The collocation of the major reduction and TC-active regions is clearly seen in a comparison between Figs. $6 \mathrm{c}$ and 6d. Similar outcomes were also obtained for the 1958-79 period (not shown). These results reveal that TCs contribute significantly to the interannual variability in the tropical western North Pacific and the South China Sea where TCs are active. The strong TC vortices apparently leave significant footprints in the seasonal means and indirectly affect the estimation of interannual variability, which is often treated as the estimation of the interannual fluctuation in the seasonal-mean fields.

\section{Intraseasonal variability}

As discussed in the introduction, TCs are often modulated by ISO, and appear in clusters in the cy- 
(a) $1980-2001$
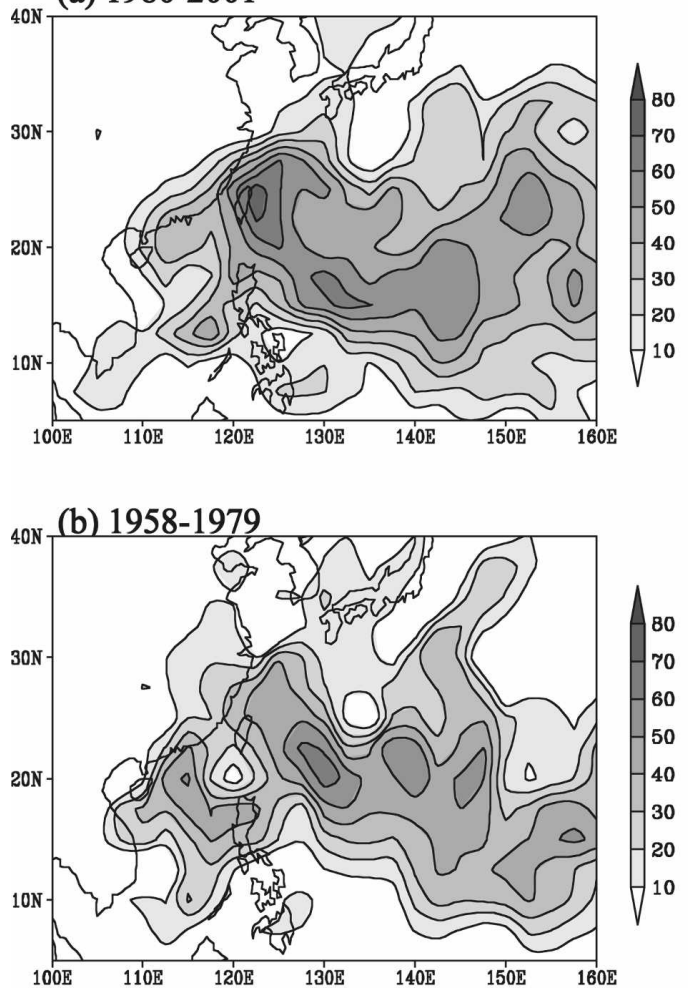

(c) $1958-2001$

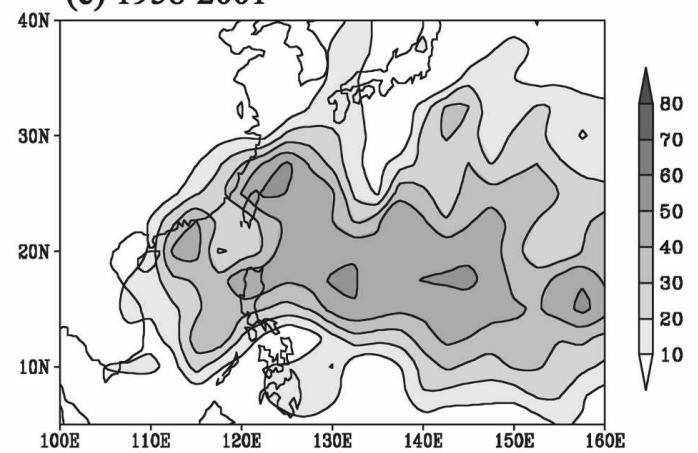

(d) TC day (1958-2001)

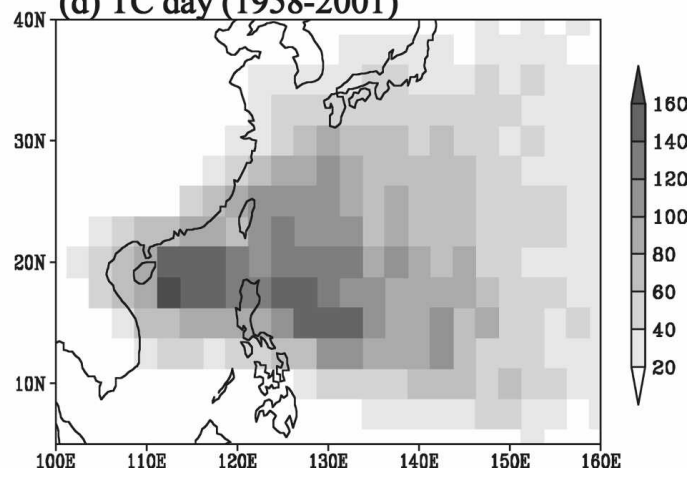

FIG. 6. Interannual variance contributed by TC in percentage: (a) 1980-2001, (b) 1958-79, (c) 1958-2001, and (d) accumulated TC occurrence distribution in 1958-2001. Contour interval is $10 \%$.

clonic phase of the ISO (e.g., Liebmann et al. 1994; Maloney and Dickinson 2003). This section explores whether this clustering effect significantly affects the intraseasonal variability (ISV) as in the interannual time scale.

The intraseasonal variance of the original and TCremoved 850-hPa vorticity fields during 1980-2001 are shown in Fig. 7. In the original field (Fig. 7a), a large variance is found in the oceanic region southwest of Taiwan and south of Japan, the South China Sea, and east of the Philippines. After removing TCs, excluding the area south of Japan, the variance in all the other regions reduces a great deal (Fig. $7 b$ ). The regions with the largest reduction, which is more than $50 \%$ in the core region, appear in the oceanic region to the east of Taiwan, the Philippines, and the South China Sea (Figs. $7 \mathrm{c}, \mathrm{d})$. These regions are also the major regions of clustered TC tracks (Fig. 5d). Similar results were obtained for 1958-79 and 1958-2001 (not shown).

To further delineate how the occurrence of TCs affect the ISV, the daily time series of area-mean vorticity in an ISO-active region $\left(15^{\circ}-30^{\circ} \mathrm{N}, 123^{\circ}-138^{\circ} \mathrm{E}\right)$, where large ISV and TC tracks were located during the 1999 typhoon season, is shown by dotted curve in Fig. 8. There were two ISO events from June to October, with peaks in late-July/early August and mid-October. These two time periods are also when the TC activities in the region are active, as indicated in the bottom of Fig. 8. This confirms the well-known fact that TCs tended to appear in the positive vorticity phase. These two ISO events can still be seen in the TC-removed time series (dashed curve in Fig. 8), but with amplitudes reduced substantially in the positive vorticity phases. The levels of reduction, shown by the light solid curve, are often larger than the TC-removed amplitudes during the peak phases, while the vorticity in the negative vorticity phases remains unchanged. The vorticity reduction shown in Fig. 8 is larger than the original vorticity in a few occasions. This is because the positive vorticity contributed by the TC to the area-mean vorticity shown in Fig. 8 is partially cancelled by the negative vorticity within the area. The original vorticity can be smaller than the vorticity reduction when the cancellation is more significant in certain periods.

Results of the spectral analysis applied to the original and TC-removed time series in Fig. 8 are shown in Fig. 9. Before applying a spectral analysis, fluctuations with periods longer than 120 days were removed to emphasize the intraseasonal time scale. In the original time series, two spectral peaks (exceeding 95\% confidence 
(a) Total

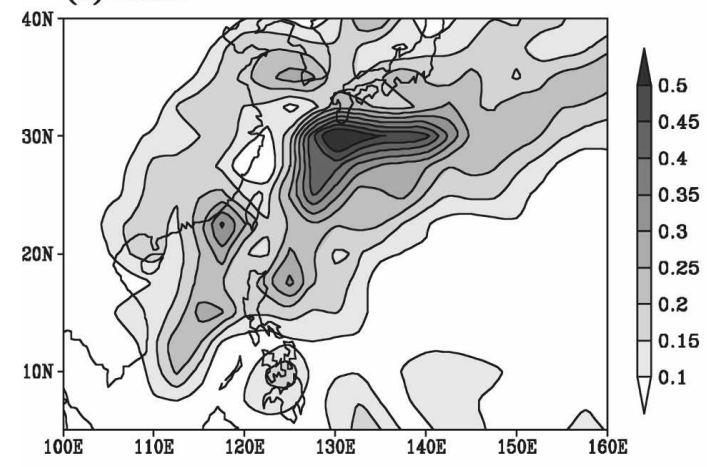

(b) TC-removed

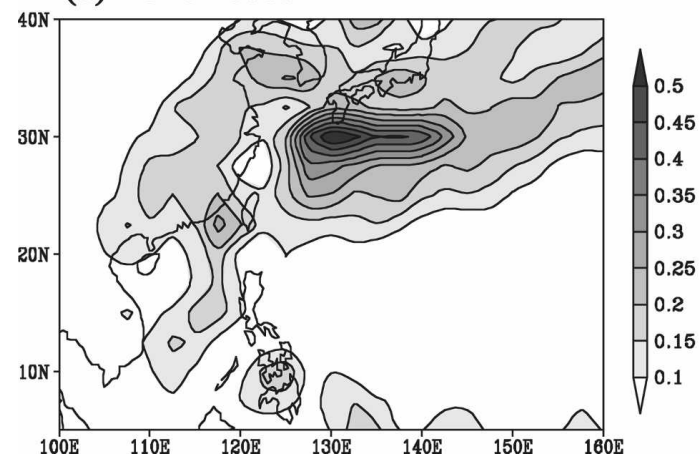

(c) TC

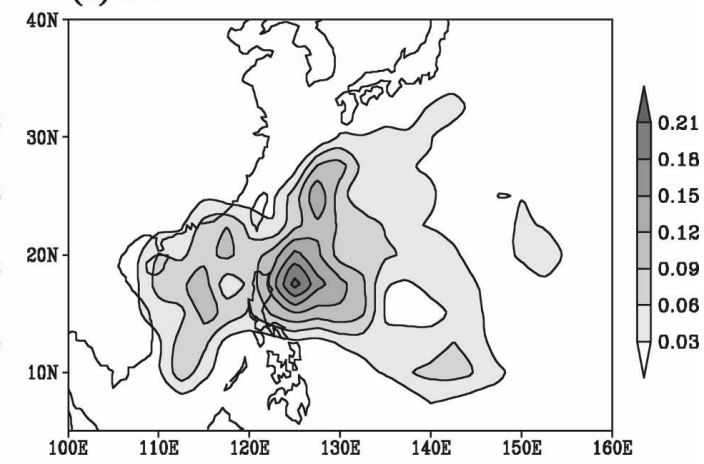

(d) Percentage

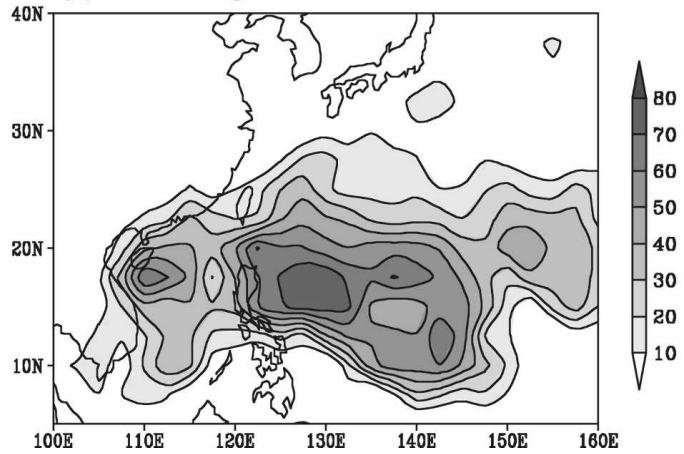

FIG. 7. Intraseasonal (20-80 days) variance of 850-hPa vorticity in 1980-2001: (a) total, (b) TC removed, (c) TC, and (d) TC contribution in percentage. Contour interval is $0.05 \times 10^{-12} \mathrm{~s}^{-2}$ in (a) and (d) and $0.03 \times 10^{-12} \mathrm{~s}^{-2}$ in (c). Contour interval is $10 \%$ in (d).

level) are found near 50 days and 17 days. After the removal of TCs, the 50-day peak drops substantially by more than $60 \%$. A huge drop is also observed at the 17-day peak. Both spectral and wavelet analysis were

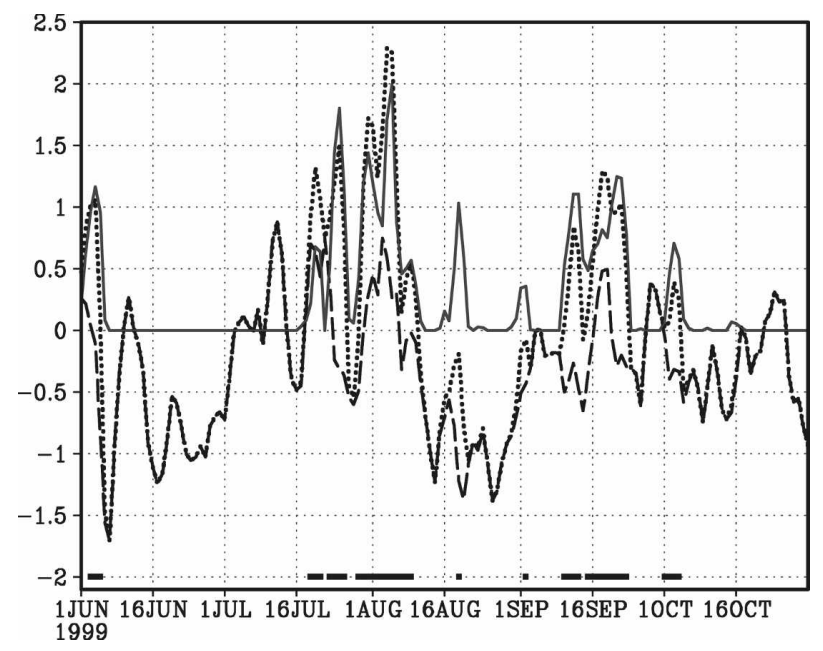

FIG. 8. Total (dotted curve), TC removed (dashed curve), and TC contribution (solid curve) time series of the $850-\mathrm{hPa}$ vorticity (unit: $\left.10^{-5} \mathrm{~s}^{-1}\right)$ averaged over $\left(15^{\circ}-30^{\circ} \mathrm{N}, 123^{\circ}-138^{\circ} \mathrm{E}\right)$ in JJASO 1999. Occurrence of TC is marked at the bottom of the figure. applied to each respective year from 1979 and 2001. Similar results were obtained.

The significant variance reduction can be viewed as the TC contribution to the ISV. The clustered TCs with strong positive vorticity enlarged the amplitude of positive vorticity in the cyclonic phase of ISO. On the con-

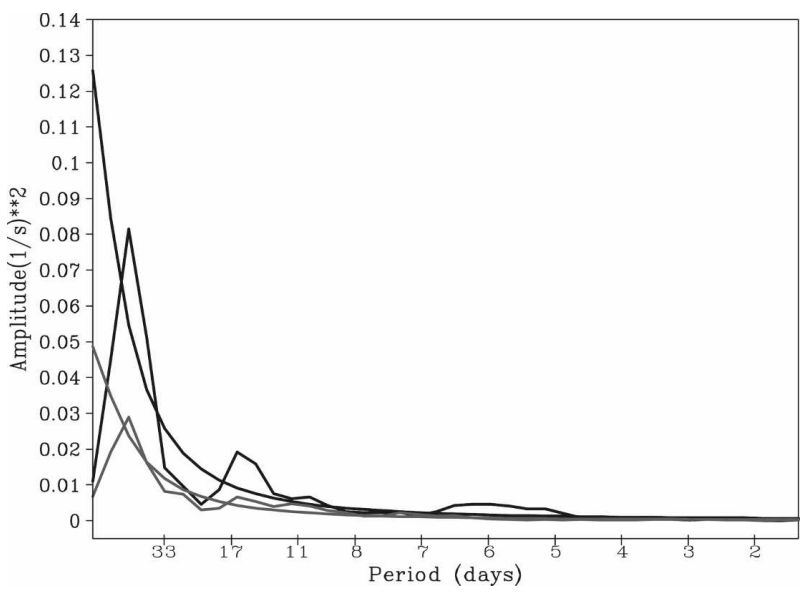

FIG. 9. Spectra of the total (dark line) and TC-removed (gray line) time series $\left(10^{-10} \mathrm{~s}^{-2}\right)$ shown in Fig. 8. The corresponding red noise spectra at $95 \%$ confidence level are shown in the smooth dark and gray curves. 
trary, the amplitude in the anticyclonic phase is virtually unaffected because much fewer TCs appear in that phase. The enlargement of the positive vorticity apparently leads to the larger variance (and stronger variability) in the intraseasonal time scale. The ISV evidently becomes larger through the clustering effect of ISO on TCs.

\section{Comparison between different analyses}

TCs may be represented differently in various analyses because of the different design of data assimilation systems and models. Influence of data resolution (e.g., difference between $2.5^{\circ}$ and $1.125^{\circ}$ resolution) on our results is another issue that requires attention. These two issues are investigated in this section by comparing the results based on the ECMWF and NCEP-NCAR reanalyses, and also the analysis of different spatial resolution. Comparisons were done for the case studies, seasonal mean, and intraseasonal variance.

The problem of spatial resolution is examined by a comparison between ERA-40 and the NCEP-NCAR reanalyses $\left(2.5^{\circ}\right.$ resolution for both $)$, and between ERA-40 and the ECMWF analysis in $1.125^{\circ}$ resolution during the 1996 typhoon season. The removing procedure was found to be effective in removing the TC from all three analyses, although the representation of TCs may vary respectively. One example is shown in Fig. 10, which presents the total $850-\mathrm{hPa}$ vorticity field and the TC vortices on 0600 UTC 26 July 1996 in all three analyses. Two typhoons lining up zonally were observed simultaneously in the western North Pacific, and were clearly identified in each analysis (Figs. 10a-c). The vortices identified in the NCEP-NCAR reanalysis were the weakest ones, while those in the ECMWF analysis of $1.125^{\circ}$ resolution exhibited the largest amplitude and sharpest structure because of the higher resolution (Figs. 10d-f). Although differences between the three analyses were notable, the identification of the TC vortices from the total field was done successfully, and the major characteristics of the TCs were all revealed. A comparison was done for every 6-hourly analysis from 1 June to 30 October 1996. Results (not shown) indicate a consistency between each analysis during the entire period.

Seasonal means estimated from the ERA-40 and the NCEP-NCAR reanalysis in the $2.5^{\circ}$ resolution, and the ECMWF analysis in the $1.125^{\circ}$ resolution in JJASO 1996 are presented in Figs. 11a-c. The ECMWF analysis in both resolutions (Figs. 11a-c) reveal more details in the spatial distribution, and generally exhibits larger amplitudes than the NCEP-NCAR reanalysis (Fig. 11b). The ECMWF analysis in the $1.125^{\circ}$ resolution shows more localized features with larger amplitudes owing to the higher resolution. Despite these discrepancies, all three analyses exhibited a similar spatial pattern, which is characterized by the positive vorticity in western China, the South China Sea, and the Philippine Sea, reflecting the extension of the monsoon trough from China to the Philippine Sea. To the north of this positive vorticity region is a zonal belt of negative vorticity, representing the subtropical anticyclone. The positive vorticity region and the TC track are collocated as in other years (not shown). After removing the TCs, the major differences in the seasonal-mean fields shown in Figs. 11d-f are 1) virtual disappearance of the positive vorticity in the Philippine Sea, 2) weakened positive vorticity in the South China Sea, and 3) enhanced zonal belt of negative vorticity. These features reflect the weakened monsoon trough and strengthened anticyclone. The major differences are the results of reduced vorticity along the TC tracks. The TC effect on the seasonal means of the three analyses reveals similar characteristics.

Because of its unique characteristics, the 2004 typhoon season is chosen for a comparison of the intraseasonal variance. This particular season was characterized by the strong in-phase relationship between intraseasonal signal and TCs (Nakazawa 2006). The record-breaking number (10) of typhoon making landfall in Japan was another interesting feature observed in that season. Our calculation (not shown) indicates a predominant 32-76-day fluctuation. Comparison of the 32-76-day intraseasonal variance of the $850-\mathrm{hPa}$ vorticity between each analysis is shown in Fig. 12. The original ISV in both the NCEP-NCAR reanalysis and the ERA-40 (both in the $2.5^{\circ}$ resolution; Figs. $12 \mathrm{a}, \mathrm{c}$ ) demonstrate similar spatial distribution, despite quantitative differences being observed. Large variances are evident in the Philippine Sea and in the oceanic region south of Japan and east of Taiwan. The ECMWF analysis again exhibits a larger variance and spatial distribution in greater detail. Figures $12 \mathrm{~b}$ and $12 \mathrm{~d}$ present the variance difference between the original and TCremoved 850 -hPa vorticity fields, that is, the TC contribution, in the NCEP-NCAR and ECMWF reanalyses, respectively. Again, both figures are characterized by similar spatial distributions, which reveal the major differences in the Philippine Sea and the oceanic region south of Japan and east of Taiwan along the TC tracks. The TC contribution can be larger than $50 \%$ along the clustered TC tracks in both analyses. This result indicates the consistency between the ECMWF and NCEP-NCAR reanalyses.

\section{Rainfall}

As shown in the previous section, TCs contribute significantly to the climate variability of the $850-\mathrm{hPa}$ 
(a) Total ECMWF 2.5

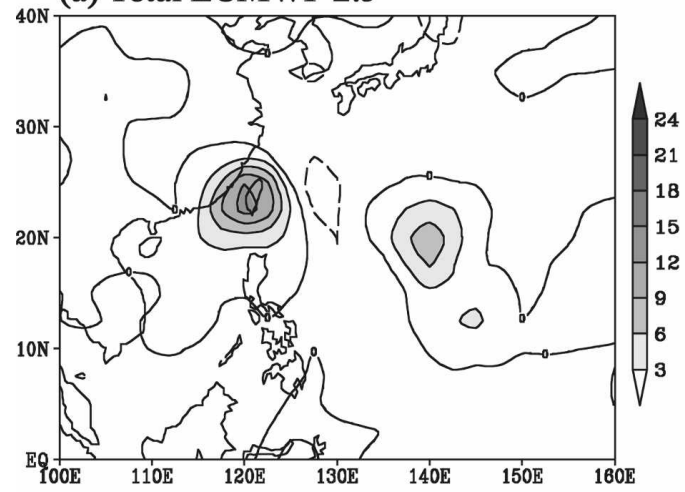

(b) Total NCEP 2.5

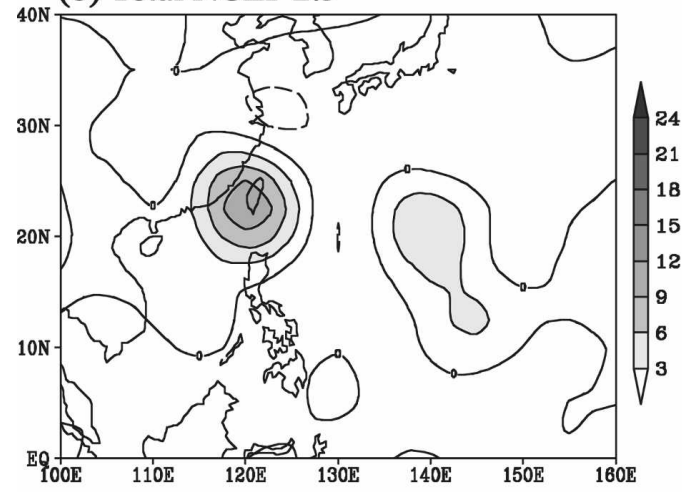

(c) Total ECMWF 1.125

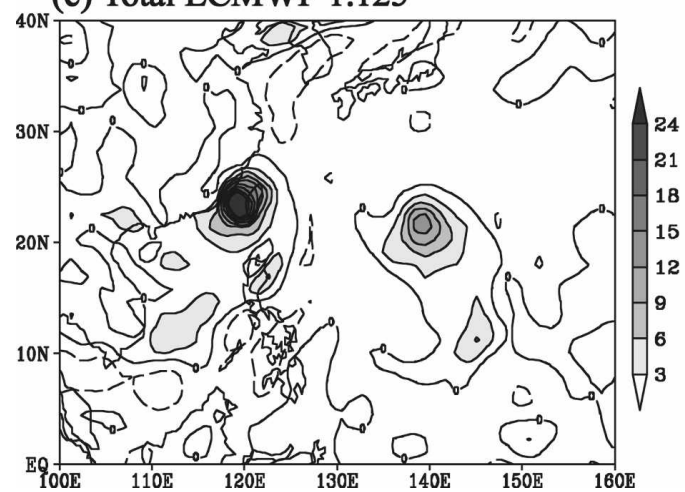

(d) TC ECMWF 2.5

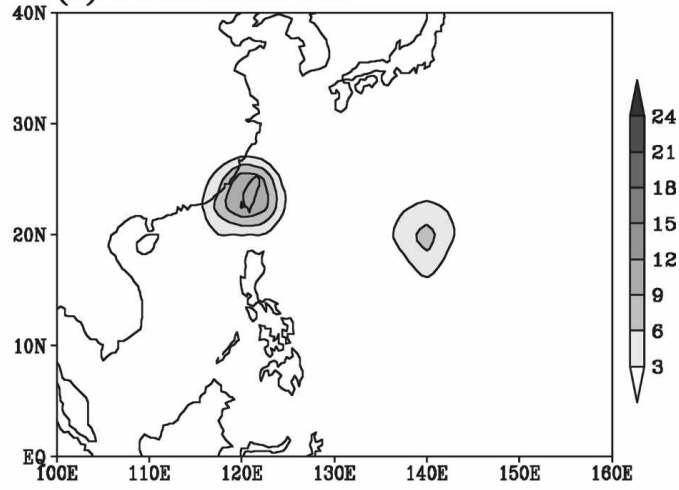

(e) TC NCEP 2.5

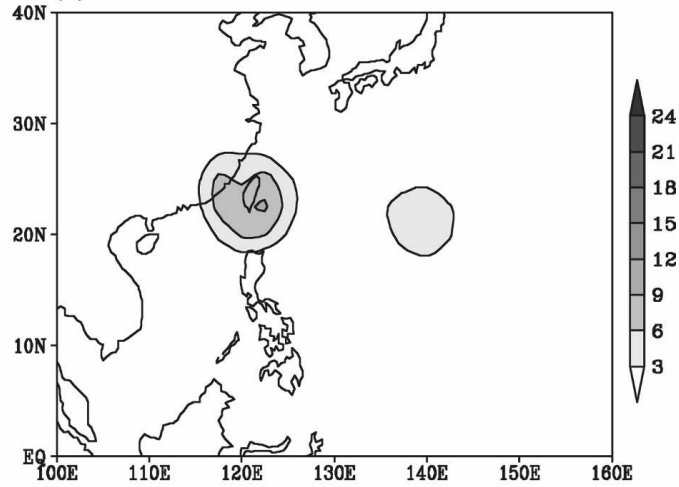

(f) TC ECMWF 1.125

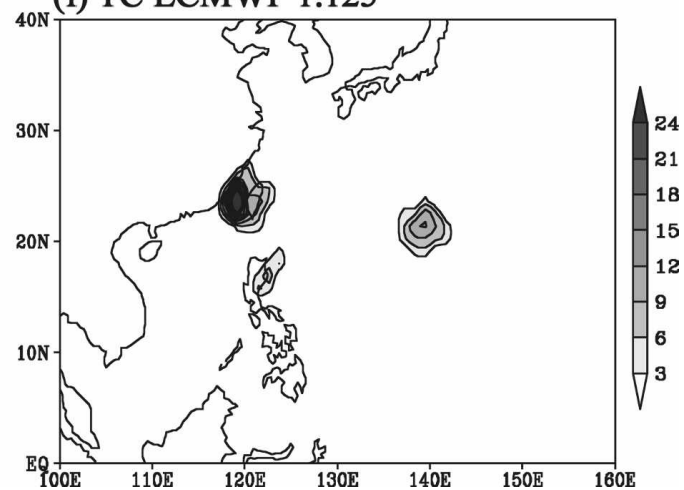

FIG. 10. (a)-(c), Total and (d)-(f) TC component of 850-hPa vorticity at 0600 UTC 26 Jul 1996: (a), (d) ECMWF analysis in $2.5^{\circ}$ resolution; (b), (e) NCEP-NCAR reanalysis in $2.5^{\circ}$ resolution; and (c), (f) ECMWF analysis in $1.125^{\circ}$ resolution. Contour interval is $3 \times 10^{-5} \mathrm{~s}^{-1}$. Solid and dashed lines denote positive and negative vorticity, respectively.

vorticity along the TC tracks. Rainfall is another important climate variable that is likely to be affected. Being a positive-definite variable, rainfall has no corresponding negative value to compensate. The heavy rainfall brought by TCs often occurs like a largeamplitude step function, and is likely to have a significant impact on the estimation of seasonal mean and interannual variability. In this section, the rainfall in Taiwan, which is on average affected by $3-4$ landfalling typhoons (i.e., named TCs) annually during the typhoon season, is analyzed as an example to demonstrate the TC contribution on the interannual variability of rainfall. Taiwan was chosen partly because of the easier access to station data for the authors. In addition, 
(a) Total ECMWF 2.5

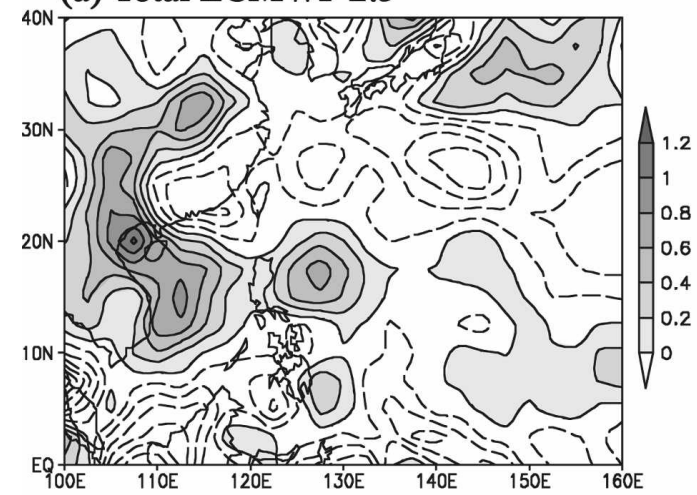

(b) Total NCEP 2.5

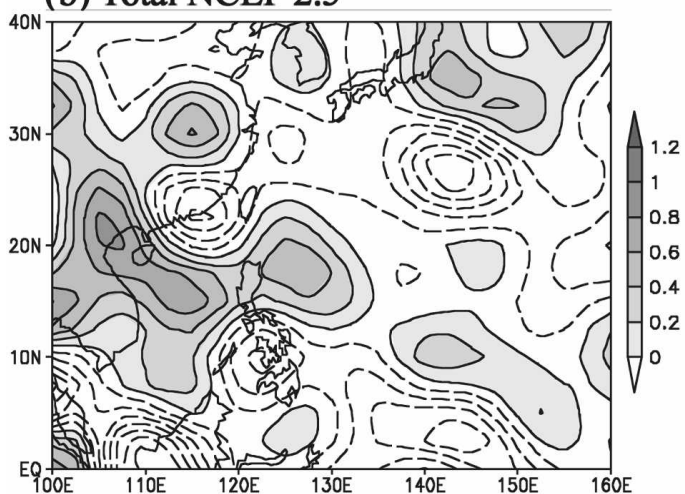

(c) Total ECMWF 1.125

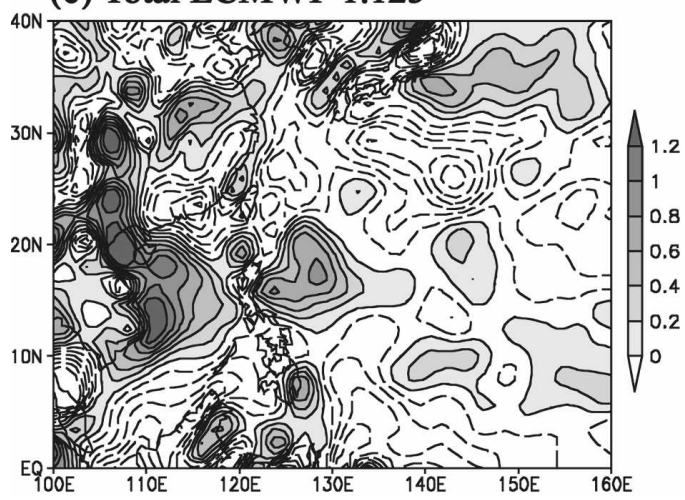

(d) TC -removed ECMWF 2.5

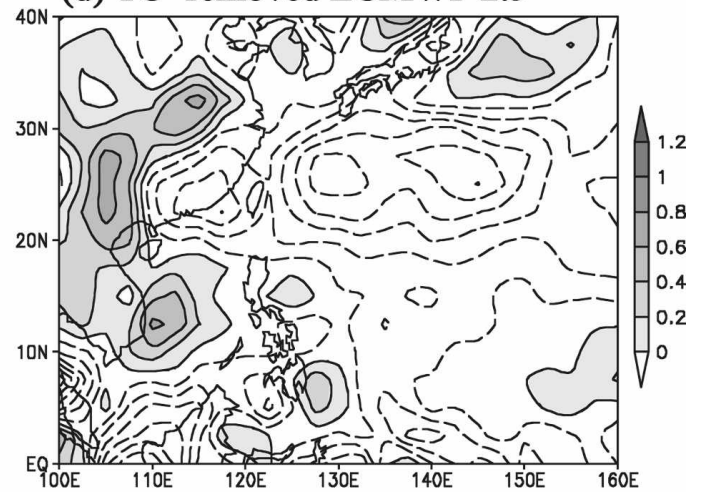

(e) TC -removed NCEP 2.5

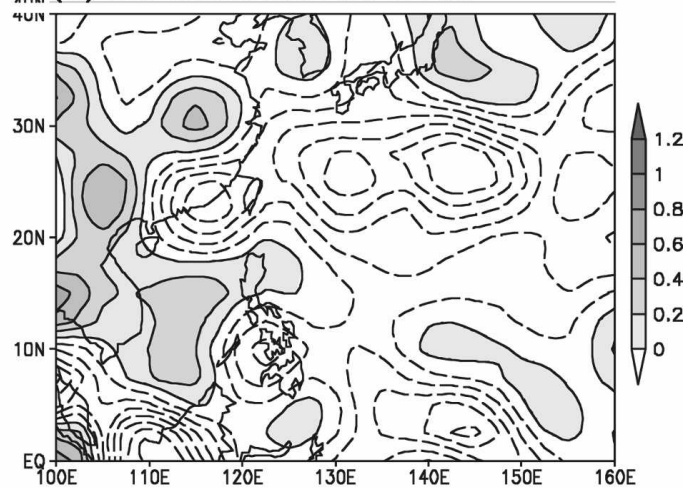

(f) TC-removed ECMWF 1.125

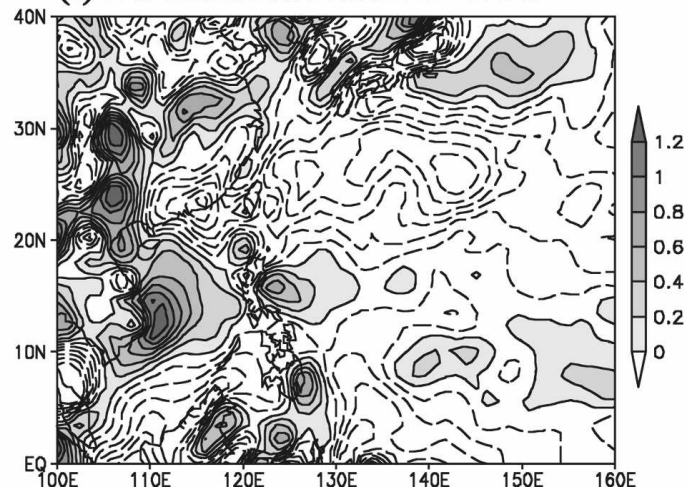

FIG. 11. Seasonal means of (a)-(c) total and (d)-(f) TC-removed 850-hPa vorticity in JJASO 1996: (a), (d) ECMWF analysis in $2.5^{\circ}$ resolution; (b), (e) NCEP-NCAR reanalysis in $2.5^{\circ}$ resolution; and (c), (f) ECMWF analysis in $1.125^{\circ}$ resolution. Contour interval is $0.2 \times 10^{-5} \mathrm{~s}^{-1}$. Solid and dashed lines denote positive and negative vorticity, respectively.

Taiwan is located in one of the favorite regions of TC tracks and its weather and climate are significantly affected by typhoons.

Rainfall data from 18 weather stations in Taiwan during 1958-2001, provided by Taiwan's Central Weather Bureau (CWB), were used in this study. The averages of these 18 weather stations, which cover the entire island quite evenly, were analyzed. Seasons in Taiwan are traditionally classified according to the dominant weather and rainfall characteristics. The annual rainfall cycle in Taiwan can be separated into spring rain, meiyu, typhoon, and winter dry seasons (Fig. 13a; Chen and Chen 2003). To depict the characteristics of the annual rainfall cycle in Taiwan, the time series of 31-day running mean of climatological-mean rainfall averaged over the $18 \mathrm{CWB}$ weather stations is shown in the thick 
(a) Total NCEP
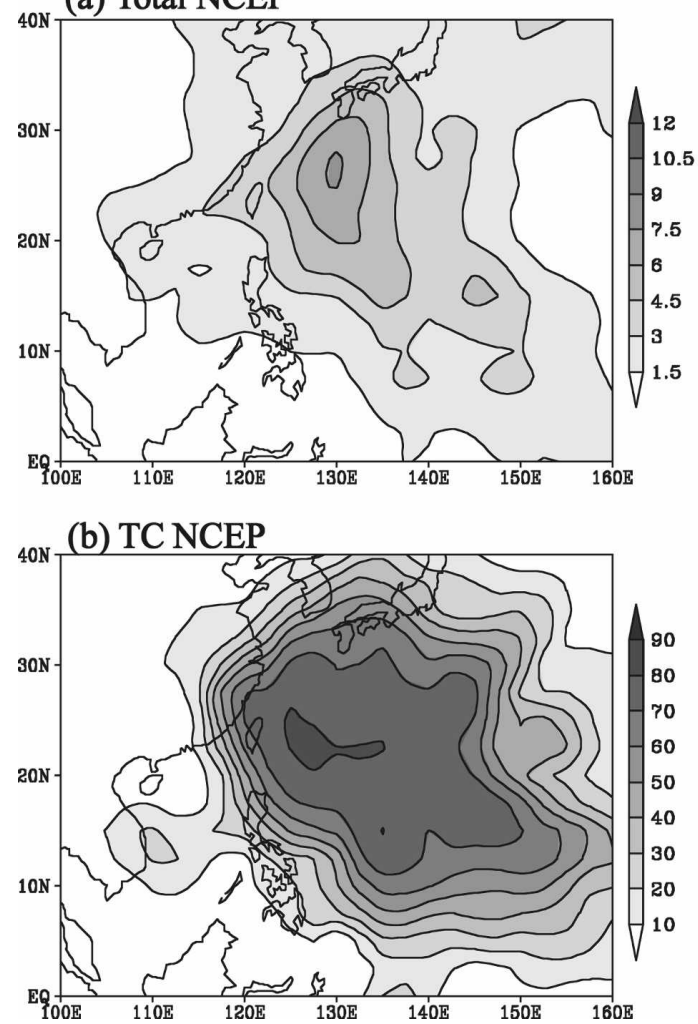

(c) Total ECMWF
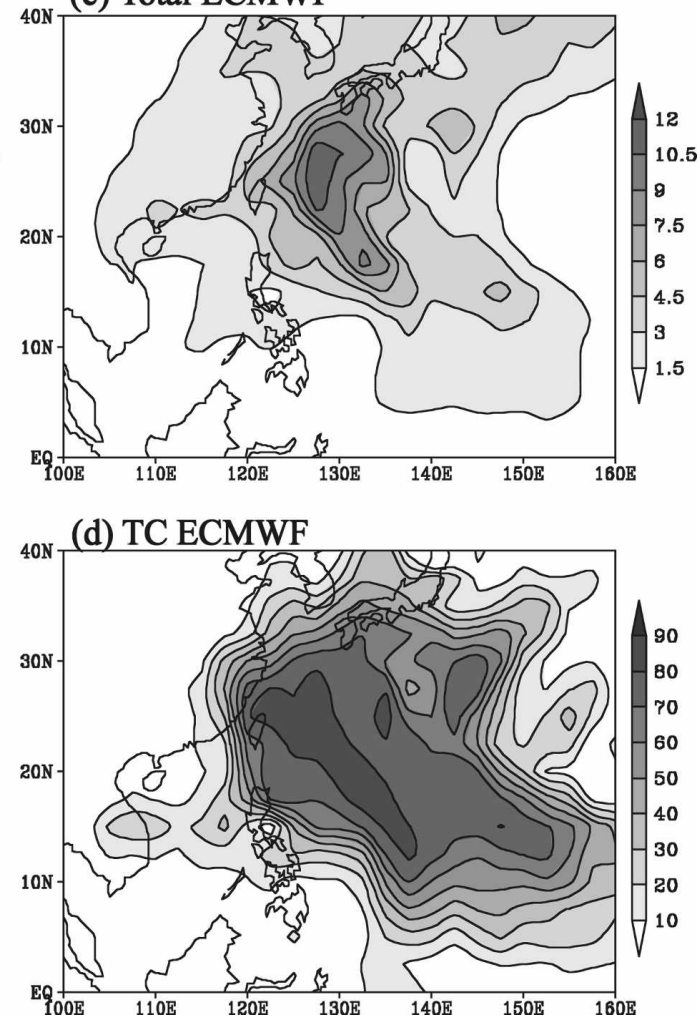

FIG. 12. (a), (c) Intraseasonal (32-76 days) variance and (b), (d) intraseasonal (32-76 days) variance contributed by TCs in JJSAO 2004 in the (a), (b) NCEP-NCAR reanalysis and (c), (d) ECMWF analysis. Contour interval is $1.5 \times 10^{-10} \mathrm{~s}^{-2}$.

black curve in Fig. 13a. The rainfall corresponding to the 25th, 50th, and 75th percentiles are also shown in dashed lines. Mei-yu (May and June) and typhoon [July to October (JASO)] seasons are the two major rainy seasons in Taiwan. The mean rainfall is between the 50th and 75th percentiles for both seasons, but is much closer to the 75th percentile in the typhoon season than in the mei-yu season. This implies that the JASO season rainfall is contributed substantially by various extremely heavy rainfall events, which are usually related to typhoons.

To estimate the potential contribution of typhoonrelated rainfall on the total rainfall during the JASO season, a designated region $\left(19^{\circ}-28^{\circ} \mathrm{N}, 117^{\circ}-125^{\circ} \mathrm{E}\right)$ surrounding Taiwan is chosen to separate the typhoonrelated rainfall (hereafter, typhoon rainfall) and the nontyphoon-related rainfall (hereafter, non-typhoon rainfall). When the center of a typhoon enters this region, the rainfall occurring in Taiwan is counted as "typhoon rain." The remaining rainfall occurring during other periods is deemed as "non-typhoon rainfall." As some typhoons decay into tropical cyclones after making landfall in Taiwan, all cases were taken into account as long as the tropical cyclones were once classified as a typhoon during their lifetime. The region used to define the typhoon rainfall was slightly changed, where it covered a larger or smaller domain to test the reliability of the results shown below. Consistency is found between the different domain sizes. The definition of the typhoon and nontyphoon rainfall cannot separate the large-scale rainfall from the rainfall contributed by the mesoscale convective systems in a typhoon. Therefore, the typhoon rainfall is likely overestimated because of the inclusion of large-scale rainfall. On the other hand, the rainfall associated with mesoscale convective systems is usually at least one order of magnitude larger than the rainfall when no typhoons exist in the vicinity. The overestimation is negligible, and will not affect the results presented here.

During JASO, the long-term average of the total rainfall is $1261.8 \mathrm{~mm}$, in which typhoon and nontyphoon rainfalls account for $43.2 \%(532.4 \mathrm{~mm})$ and $56.8 \%(699.4 \mathrm{~mm})$, respectively. During the 123-day JASO season, the $43.2 \%$ total rainfall contributed by typhoons occurs on average for only 14 days, while the remaining $56.8 \%$ occurs in the other 109 nontyphoon 

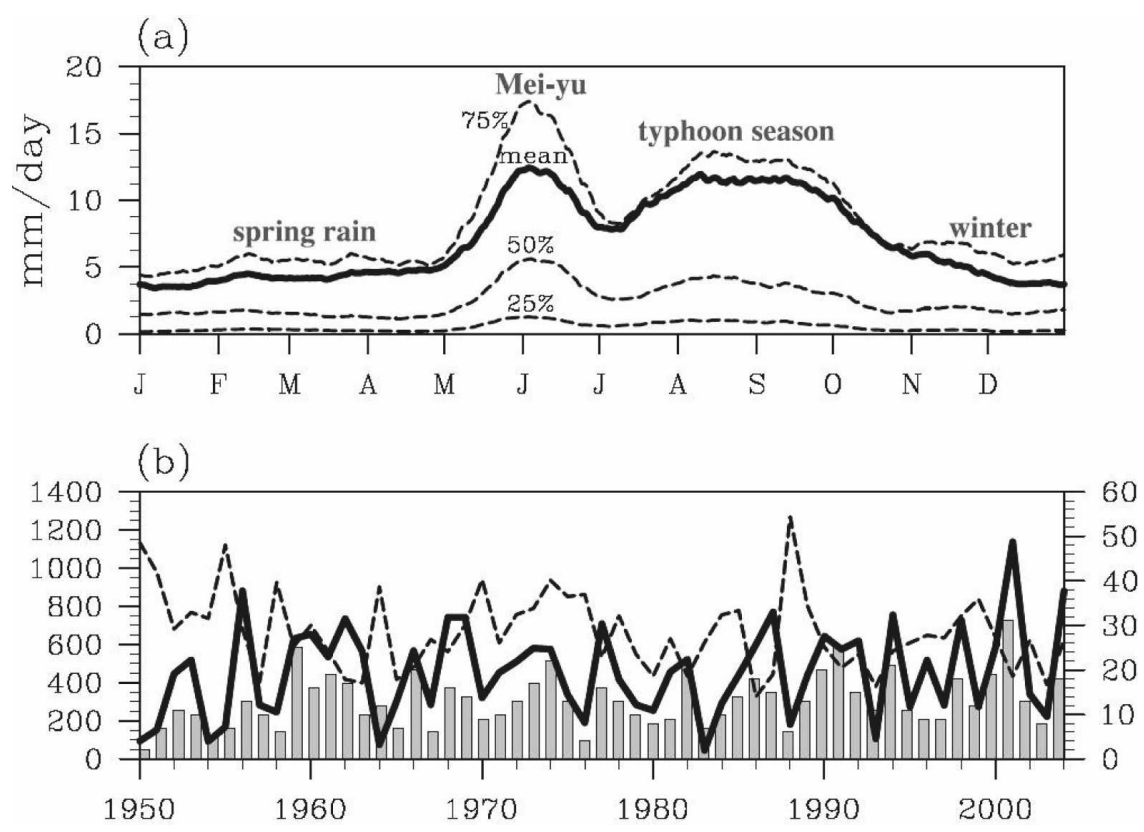

FIG. 13. (a) The 31-day running means of rainfall seasonal cycle in Taiwan (thick dark line) and the corresponding rainfall at the 25,50, and 75 percentiles. (b) Typhoon rainfall (thick solid line; mm; left axis), nontyphoon rainfall (dashed line; mm; left axis), and number of typhoon days (bar; days; right axis) in Taiwan during 1950-2004.

days. This implies that a handful of short-term extreme rainfall events related to typhoons can have a large impact on the monthly and seasonal rainfall in Taiwan.

Seasonal means of typhoon and nontyphoon rainfall from 1950 to 2004 are shown in Fig. 13b. Both types of rainfall fluctuate significantly from year to year. The interannual standard deviations are 239.4 and $205.5 \mathrm{~mm}$ for the seasonal-mean typhoon and nontyphoon precipitation, respectively. The largest contribution of typhoon rainfall accounting for $65.6 \%$ of total rainfall occurred in 1986, while the smallest contribution taking up only $7.7 \%$ occurred in 1964 . The number of days with typhoon affecting Taiwan is also shown in Fig. 13b, which reveals a fluctuation between 2 and 30 days. The level of contribution from the typhoon is closely associated with the number of typhoon day. The correlation coefficient between the two time series is 0.78 . This is expected because a typhoon usually brings torrential rainfall to Taiwan. Monthly and even seasonal rainfall in Taiwan can be changed from below normal to above normal simply by one single typhoon landfall event. Inclusion of the typhoon rainfall significantly increases the interannual standard deviation from 205.5 (of nontyphoon rainfall) to $247.7 \mathrm{~mm}$ (of total rainfall). This clearly reflects the significant contribution of typhoon rainfall to the interannual variability of total rainfall. The results presented above reveal a big challenge for the seasonal rainfall forecast in the JASO season, as almost half of the total rainfall, along with a significant portion of the interannual variance in the Taiwan's typhoon season, is contributed by a handful of extreme rainfall events associated with typhoons.

\section{Conclusions and discussion}

By estimating the differences between the original and TC-removed fields, this study reveals that TCs contribute a great deal to the seasonal mean and the intraseasonal and interannual variability of the $850-\mathrm{hPa}$ vorticity along the TC tracks.

This large reduction in both seasonal mean and variance can be explained as follows. While the lowfrequency large-scale circulation has a clustering effect on TCs, the latter tends to occur with large amplitude in the positive vorticity background flow, and significantly enhances the total strength of the positive vorticity. Conversely, when no TC exists or when only the synoptic anticyclone is found, the contribution to the total vorticity field from the synoptic- and mesoscale disturbances is relatively small. This is because the negative vorticity associated with these disturbances is much weaker than the positive vorticity of TCs. The contribution of TCs is therefore not offset by the disturbances of the negative vorticity. This contrast leads to the enlargement of the mean and variance, where the effects, which account for more than $50 \%$ of variance along TC 
tracks, are found in both intraseasonal and interannual variability. Similar situations can also occur in the rainfall, which is positive-definite and cannot be balanced by negative values. Strong impacts from the typhoon rainfall on the seasonal mean and interannual variance of the rainfall in Taiwan is found.

In reality, the relationship between tropical cyclones and the large-scale circulation is nonlinear. Bearing this in mind, our study took an unconventional approach to remove TC vortices from the circulation to demonstrate that even a simple arithmetic approach can greatly affect the computed mean and variance in both intraseasonal and interannual time scales. Since the intraseasonal and interannual variability is usually interpreted based on the low-pass filtered data or seasonal means, the contribution of the TC activity, which is imprinted in these means, can possibly be viewed as climate variability. Similar effects are likely to occur in other TC-prone regions. Further studies are needed to evaluate this possible impact.

Our finding raises a question about the definition of climate variability in the TC-prone regions. Traditionally, climate variability is often interpreted as the variability of low-frequency climatic perturbations. Our results, however, point out that these climatic perturbations may contain the contribution from TCs, which fluctuate in much shorter periods and smaller spatial scale. In the region such as the tropical western North Pacific, where the meso-synoptic-scale and large-scale systems are closely intertwined, and the multiscale interaction is likely one of the key processes affecting the climate variability, the contribution from the severe weather systems like TCs has to be taken into account to understand the mechanisms leading to the climate variability.

In the tropical western North Pacific, the tropical cyclone often has a lifetime longer than 10 days. As the moving tropical cyclones own a strong and long-lasting energy source, large-scale circulations are likely induced, followed by energy emanation to remote regions. This feedback may affect the environmental flow, such as the subtropical anticyclone and monsoon trough, and leave notable footprints in the climate variability in the regions away from TC tracks. This potential effect cannot be estimated by the methodology adopted in the present study and will be explored in future works. Another problem is the coarse resolution of the datasets used in this study. Although the TCs are reasonably represented, the strength of the TCs is underestimated and the spatial structure is not as sharp as in the real world. As a result, the actual contribution of TCs to the climate variability cannot be accurately estimated. Moreover, the contribution is likely underes- timated. However, despite not being able to exactly quantify the effect, this research explains in a qualitative sense why the contribution from TCs cannot be overlooked.

Most of the general circulation models used to simulate past climate suffers from the poor simulation of the climate variability in the tropical western North Pacific during the boreal summer (Wang et al. 2004). The results reported here imply that the inability to resolve and simulate TCs may be one of the key weaknesses of the GCM leading to the poor simulation. Using coarseresolution GCM may lead to an inaccurate climate simulation and prediction in the intraseasonal, interannual, and, perhaps, even climate change time scales. High-resolution models that are able to reasonably simulate the ensemble effect of TCs, at least in the statistical sense, seem needed to resolve the multiscale interaction and to produce better simulations of the climate variability in TC-prone regions, such as the tropical western North Pacific.

Acknowledgments. The authors thank anonymous reviewers for their valuable comments. This study is supported by the National Science Council in Taiwan under Grant NSC-95-2111-M-002-010-MY3.

\section{REFERENCE}

Chan, J. C. L., 1985: Tropical cyclone activity in the northwest Pacific in relation to the El Niño/Southern Oscillation phenomenon. Mon. Wea. Rev., 113, 599-606.

- 2000: Tropical cyclone activity over the western North Pacific associated with El Niño and La Niña events. J. Climate, 13, 2960-2972.

Chen, C.-S., and Y.-L. Chen, 2003: The rainfall characteristics of Taiwan. Mon. Wea. Rev., 131, 1323-1341.

Chen, T.-C., S.-P. Weng, N. Yamazaki, and S. Kiehne, 1998: Interannual variation in the tropical cyclone formation over the western North Pacific. Mon. Wea. Rev., 126, 1080-1090.

—, S.-Y. Wang, M.-C. Yen, and W. A. Gallus Jr., 2004: Role of the monsoon gyre in the interannual variation of tropical cyclone formation over the western North Pacific. Wea. Forecasting, 19, 776-785.

Chia, H. H., and C. F. Ropelewski, 2002: The interannual variability in the genesis location of tropical cyclones in the northwest Pacific. J. Climate, 15, 2934-2944.

Elsberry, R. L., 2004: Monsoon-related tropical cyclones in East Asia. East Asian Monsoon, C.-P. Chang, Ed., World Scientific Series on Meteorology of East Asia, Vol. 2, World Scientific, 463-498.

Gray, W. M., 1979: Hurricanes: Their formation, structure and likely role in the tropical circulation. Meteorology over the Tropical Oceans, D. B. Shaw, Ed., Royal Meteorological Society, 155-218.

Heta, Y., 1990: An analysis of tropical wind fields in relation to typhoon formation over the western Pacific. J. Meteor. Soc. Japan, 68, 65-76.

Ho, C.-H., J.-J. Baik, J.-H. Kim, D.-Y. Gong, and C.-H. Sui, 2004: 
Interdecadal changes in summertime typhoon tracks. J. Climate, 17, 1767-1776.

Kurihara, Y., M. A. Bender, and R. J. Ross, 1993: An initialization scheme of hurricane models by vortex specification. Mon. Wea. Rev., 121, 2030-2045.

,,-- R. E. Tuleya, and R. J. Ross, 1995: Improvements in the GFDL hurricane prediction system. Mon. Wea. Rev., 123, 2791-2801.

Landsea, C. W., 2000: El Niño-Southern Oscillation and the seasonal predictability of tropical cyclones. El Niño and the Southern Oscillation: Multiscale Variability and Global and Regional Impacts, H. F. Diaz and V. Markgraf, Eds., Cambridge University Press, 149-181.

Liebmann, B., H. H. Hendon, and J. D. Glick, 1994: The relationship between tropical cyclones of the western Pacific and Indian Ocean and the Madden-Julian Oscillation. J. Meteor. Soc. Japan, 72, 401-412.

Maloney, E. D., and M. J. Dickinson, 2003: The intraseasonal oscillation and the energetics of summertime tropical western
North Pacific synoptic-scale disturbances. J. Atmos. Sci., 60, 2153-2168.

Nakazawa, T., 1986: Intraseasonal variations of OLR in the tropics during the FGGE year. J. Meteor. Soc. Japan, 64, 17-34.

- 2006: Madden-Julian Oscillation activity and typhoon landfall on Japan in 2004. SOLA, 2, 136-139.

Uppala, S. M., and Coauthors, 2005: The ERA-40 Re-Analysis. Quart. J. Roy. Meteor. Soc., 131, 2961-3012.

Wang, B., and J. C. L. Chan, 2002: How strong ENSO events affect tropical storm activity over the western North Pacific. J. Climate, 15, 1643-1658.

_ I.-S. Kang, and J.-Y. Lee, 2004: Ensemble simulations of Asian-Australian monsoon variability by 11 AGCMs. J. Climate, 17, 803-818.

Wu, C.-C., T.-H. Yen, Y.-H. Kuo, and W. Wang, 2002: Rainfall simulation associated with Typhoon Herb (1996) near Taiwan. Part I: The topographic effect. Wea. Forecasting, 17, 1001-1015. 